\title{
Youth access to cigarettes in six sub-Saharan African countries
}

Rachna Chandora ${ }^{1}$, Yang Song ${ }^{2}$, Martine Chaussard ${ }^{3}$, Krishna Mohan Palipudi ${ }^{4}$, Kyung Ah Lee $^{4}$, Nivo Ramanandraibe ${ }^{5}$, Samira Asma ${ }^{2}$, on behalf of GYTS collaborative group

${ }^{1}$ CDC Foundation, Atlanta, GA, USA

${ }^{2}$ Division of Global Health Protection, Centers for Disease Control and Prevention (CDC), Atlanta, GA, USA

${ }^{3}$ American Cancer Society, Atlanta, GA, USA

${ }^{4}$ Office on Smoking and Health, National Center for Chronic Disease Prevention and Health Promotion, CDC, Atlanta, GA, USA

${ }^{3}$ World Health Organization, Regional Office for Africa, Brazzaville, Congo-Brazzaville

The findings and conclusions in this report are those of the authors and do not necessarily represent the official position of the Centers for Disease Control and Prevention.

Abstract: 203 words

Text: 2,506 words

Contact:

Rachna Chandora, MPH

CDC Foundation

55 Park Place, Suite 400

Atlanta, GA 30324

Email: rchandora@cdcfoundation.org

Phone: 404-443-1147

(C) 2016. This manuscript version is made available under the Elsevier user license http://www.elsevier.com/open-access/userlicense/1.0/ 


\begin{abstract}
Objective. Tobacco smoking is initiated and established mostly during adolescence. The World Health Organization (WHO) Framework Convention on Tobacco Control (FCTC) Article 16 outlines the obligation of parties to prohibit the sale of tobacco products to minors. This study examined where and how student smokers obtain cigarettes.
\end{abstract}

Methods. We examined Global Youth Tobacco Survey (GYTS) data from 2009-2011 on cigarette access among students aged 13-15 in six sub-Saharan African countries.

Results. In all countries analyzed, over $20 \%$ of student smokers obtained their cigarettes in a store or shop (52.6\% in South Africa, 37.7\% in Republic of Congo, 28.2\% in Swaziland, 27.4\% in Cote d'Ivoire, 26.9\% in Ghana, and $22.6 \%$ in Uganda). In Cote d'Ivoire and South Africa, $68.9 \%$ and $68.7 \%$ of student cigarette smokers, respectively, were not refused the sale of cigarettes because of age. The percentage of students who were offered free cigarettes by a tobacco company representative ranged from $4.7 \%$ in Cote d'Ivoire to $12.1 \%$ in South Africa.

Conclusions. The method of obtaining cigarettes and access to cigarettes among students varies among sub-Saharan African countries. Adopting and enforcing interventions that prevent youth from accessing tobacco products could be an effective strategy for reducing smoking initiation among youth in subSaharan African countries.

Keywords: accessibility, adolescents, cigarettes, control, GYTS, legislation, smoking, sub-Saharan Africa, supply, tobacco 


\section{Introduction}

Tobacco use is the leading cause of premature death and disease in the world, resulting in approximately six million deaths annually (1). About $20 \%$ of the world's adult population smokes cigarettes, and the majority of smokers first try smoking as youth $(2,3)$. Evidence shows that individuals who start smoking during adolescence are more likely to continue smoking into adulthood (3), and are less likely to quit smoking than are those who initiate smoking later in life (4). Additionally, studies have shown that strict enforcement of laws prohibiting cigarette sales to youth through consistent compliance checks can lead to reductions in youth smoking (5).

Compared to many other regions, tobacco use prevalence remains relatively low in sub-Saharan Africa, but consumption of cigarettes and other types of tobacco products is rising in the region as tobacco companies increasingly target low- and middle-income countries (LMICS) and seek to build a larger consumer base among youth populations (6). Between 2005 and 2010, the volume of cigarette sales declined in Western Europe and North America, while it increased in the Middle East and Africa by $11.8 \%$ (7). The relatively low prevalence of tobacco use in sub-Saharan Africa presents a unique opportunity to prevent a tobacco epidemic in the region and curb the harmful consequences of tobacco use. Tobacco control measures in the region could focus on a prevention strategy that includes policies to prevent youth initiation (8). Evidence suggests that these policies are best implemented as part of a comprehensive tobacco control program that includes: raising cigarette prices through taxation; implementing warnings about the dangers of cigarettes; prohibiting tobacco advertising, promotion, and sponsorship; and creating smoke-free environments (3). Understanding where and how youth obtain and access their cigarettes can help inform effective program and policy action that aims to reduce tobacco use prevalence among youth.

Article 16 of the World Health Organization (WHO) Framework Convention on Tobacco Control (FCTC), an international treaty which sets forth legal obligations for Parties to reduce the supply and demand of tobacco, specifically outlines the obligation of Parties to "prohibit the sales of tobacco products to persons under the age set by domestic law, national law or eighteen" and "prohibit or promote the prohibition of the distribution of free tobacco products to the public and especially minors" (9). Each of the countries in the analysis have signed and ratified the WHO FCTC; however, the enactment of WHO

Abbreviations: FCTC, Framework Convention on Tobacco Control; GYTS, Global Youth Tobacco Survey; LMIC, low- and middle-income countries; WHO, World Health Organization. 
FCTC compliant comprehensive tobacco legislation varies by country. The WHO FCTC was not signed and ratified by Cote d'Ivoire until after the data for this study were collected. Ghana, Republic of Congo, South Africa, and Swaziland have legislation defining the legal age for purchasing cigarettes as 18 years and older, Uganda recently enacted legislation delineating 21 as the legal age to purchase cigarettes, and Cote d'Ivoire does not have legislation defining a legal age for purchasing cigarettes.

Youth accessibility to cigarettes is a topic that remains unexplored in sub-Saharan Africa. This study examined where and how students in six sub-Saharan African countries obtain cigarettes.

\section{Methods}

Data were obtained from the Global Youth Tobacco Survey (GYTS). The GYTS is a standardized, schoolbased survey that collects data on students aged 13-15 years. To maintain comparability across countries and over time, the questionnaire contains a core set of 54 standard questions. The survey was developed in English and is translated into national and local languages as necessary. The questionnaire is then back translated to English to ensure accuracy $(10,11)$.

The GYTS uses a two-stage cluster sample design to select a representative sample of students from each country. All schools in a geographically defined area that contain any of the identified grades are included in the sampling frame. At the first stage, the probability of schools being selected is proportional to the number of students enrolled in the specific grades. At the second sampling stage, classes within the selected schools are randomly selected. All students in selected classes attending school the day the survey is administered are eligible to participate, and student participation is voluntary and anonymous using self-administered questionnaire $(10,11)$.

Data were available for six sub-Saharan African countries: Cote d'Ivoire (2009), Ghana (2009), Republic of Congo (2009), South Africa (2011), Swaziland (2009), and Uganda (2011). These sub-Saharan African countries were included in the analysis because they had data that were recently collected, publicly available, and had complete information on all the indicators examined in the study.

Among students aged 13-15, we examined prevalence of current cigarette smoking, method of obtaining cigarettes, refusal of sales due to age, and offer of free cigarettes. The prevalence of current smoking was defined as the percentage of students who reported that they smoked a cigarette one or 
more days in the past 30 days. Students classified as current smokers were then asked about their primary mode of obtaining cigarettes. Cigarette accessibility was assessed by the question, "During the last 30 days, how did you usually get your own cigarettes?" Response options were: "I bought them in a store, shop or from a street vendor"; "I bought them from a vending machine"; "I gave someone money to buy them for me"; "I borrowed them from someone else"; "I stole them"; "an older person gave them to me"; or "I got them some other way". Additionally, student smokers who were refused the sale of cigarettes due to age were identified by the question, "During the past 30 days (one month), did anyone ever refuse to sell you cigarettes because of your age?" All survey respondents (smokers and non-smokers) were asked, "Has a cigarette representative ever offered you a free cigarette?"

A weighting factor was applied to each student record to adjust for nonresponse (by school, class, and student) and variation in the probability of selection at the school and class levels. A final adjustment summed the weights by grade and sex to the population of school children in the selected grades in each sample site $(10,11)$. Prevalence was calculated as a percentage, with a $95 \%$ confidence interval (CI). All analyses were performed separately for each country using SUDAAN 10.0, accounting for effects of complex survey design.

\section{Results}

In the six countries examined in the study, the overall sample size ranged from 1,141 in the Republic of Congo to 4,171 in Ghana, while the overall response rate ranged from $69.1 \%$ in South Africa to $97.0 \%$ in Swaziland (Table 1). The current cigarette smoking prevalence among 13-15 year old students was lowest in Ghana (3.6\%) and highest in Cote d'Ivoire (13.7\%) (Table 2). Student smokers' method of obtaining cigarettes varied across the region, but in all the countries examined in this study, with the exception of Cote d'Ivoire, the most common method of obtaining cigarettes was buying them from a store or shop. In all six countries, more than $20 \%$ of smokers reported buying cigarettes from a store or shop. The percentage of student smokers purchasing cigarettes from a store or shop was highest in South Africa (52.6\%) and Republic of Congo (37.7\%). Cote d'Ivoire was unique in that the most common method of obtaining cigarettes was getting them from an older person (33.2\%) (Table 2).

The percentage of student smokers that gave someone else money to buy cigarettes ranged from $4.1 \%$ in Cote d'Ivoire to $21.1 \%$ in Uganda. The percentage of student smokers borrowing cigarettes ranged 
from 3.2\% in Swaziland to $17.7 \%$ in Cote d'Ivoire. The percentage of student smokers stealing cigarettes was lowest in Cote d'Ivoire (1.9\%) and highest in Swaziland (16.9\%) (Table 2).

In Cote d'Ivoire (68.9\%), Ghana (53.8\%), South Africa (68.7\%), and Swaziland (56.9\%), the majority of student smokers who tried to buy cigarettes in a store or shop were not prevented from purchasing cigarettes because of age. All students, irrespective of current smoking status, were asked if a cigarette company representative has ever offered them a free cigarette. The percentage of students who had been offered a free cigarette ranged from $4.7 \%$ in Ghana to $12.1 \%$ in South Africa (Table 2).

\section{Discussion}

The findings from this study reveal that just as smoking prevalence and consumption patterns vary across the sub-Saharan African region, the method of obtaining cigarettes and access to cigarettes among student smokers also differs. Additionally, the implementation of tobacco legislation varied by country, specifically as it related to defining a legal age to purchase cigarettes (Table 3).

South Africa was the only country in the study to have a law prohibiting the sale of cigarettes to minors at the time that GYTS was administered. Despite the law, the country has the highest percentage of students being able to purchase cigarettes in stores or shops (52.6\%), and over $68 \%$ of student smokers were not refused cigarette sales due to age. South Africa's 1993 Tobacco Products Control Act states that "no person shall sell or supply any tobacco products to any person under the age of 18 years" and "no manufacturer, distributer, importer or retailer of tobacco products, or any person or agent acting on behalf of the manufacturer, distributer, importer or retailer, shall for free, or at a reduced price, other than a normal trade discount - distribute any tobacco product" (12). Our findings, supported by earlier studies, suggest that if laws prohibiting cigarette sales to youth are not enforced, they do not adequately deter illegal sales, and have limited effect on reducing youth smoking prevalence (5). Additionally, failure to enforce age of sale laws may convey a message to youth that tobacco control laws do not need to be taken seriously and undermines other tobacco prevention and control efforts (13).

At the time of GYTS implementation in Ghana, Republic of Congo, Swaziland, and Uganda, these countries did not have legislation outlining a legal age to purchase cigarettes. The survey found that while student smoking prevalence varied between the four countries, over $20 \%$ of student smokers in 
each country purchased cigarettes in stores or shops. Legislation prohibiting tobacco sales to minors was introduced in Ghana in 2012, Republic of Congo in 2012, Swaziland in 2013, and Uganda in 2015; however, the provisions and enforcement levels of each law varies by country. Republic of Congo and Swaziland's laws require that signs be posted at the point of sale indicating the prohibition of tobacco products to minors, include requirements to verify age of purchaser, prohibit the placement of tobacco products on open store shelves, and apply penalties for violation and non-compliance, while Ghana's law does not have such requirements (14-16). Uganda recently introduced a comprehensive tobacco control law in line with many of the recommendations outlined in the WHO FCTC (17). The bill outlines stringent regulations on the distribution, sale, and use of tobacco products, and it specifically prohibits the supply and sale of tobacco products to and by minors (18). If the bill is strictly enforced, it could curb a possible future increase in smoking prevalence by preventing youth smoking initiation (19-20). Future rounds of GYTS could potentially provide an opportunity to assess the impact of the laws in each of these countries on youth smoking prevalence and cigarette accessibility.

Every country assessed, with the exception of Cote d'Ivoire, had signed and ratified the WHO FCTC at the time that GYTS was implemented in the country. Cote d'Ivoire ratified the WHO FCTC one year after the survey was conducted. While the WHO FCTC has entered into full force in each of the countries, the enactment of WHO FCTC compliant comprehensive tobacco legislation varies by country, specifically as it relates to outlining a legal age to purchase cigarettes. By signing and ratifying the WHO FCTC, these countries have shown commitment to continually and substantially reduce the prevalence of tobacco use and exposure to tobacco smoke (21).

Studies have shown that youth access laws are most effective when they are coupled with comprehensive merchant and community educational campaigns (22), as well as strict enforcement through regular compliance checks and significant penalties for non-compliance $(5,19,23)$. Essential elements of successful youth access laws include education campaigns about legal requirements to both retailers and the public, mobilization of community support, retail compliance through frequent and random inspections, implementing a graduated penalty structure, restricting self-service of tobacco products, and prohibiting free samples and sales of single cigarette sticks $(5,20,24)$. Additionally, in environments with limited resources for tobacco control, selective enforcement of laws near schools can deter underage smoking (25). 
Countries have many opportunities to reduce youth tobacco smoking by enacting and enforcing tobacco control legislation and mobilizing community support through education. Countries seeking to maximize the effectiveness of tobacco control legislation defining a legal age to purchase cigarettes should focus efforts on enforcement of legislation through regular compliance checks and graduated penalties for non-compliance, coupled with educational campaigns. Additionally, such efforts may show the greatest impact in countries like the Republic of Congo and South Africa, where a large percentage of students purchase cigarettes in stores or shops (37.7\% and 52.6\%, respectively). Countries that lack tobacco control legislation may consider laws with provisions for the prohibition and enforcement of tobacco products sales to minors. In signing and ratifying the WHO FCTC, all six countries in this study have committed to reducing the prevalence of tobacco use in their countries. A critical component of reducing tobacco use is the enactment of strong tobacco control legislation that restricts youth access to tobacco (5).

\section{Limitations}

This study is subject to at least five limitations. First, the analysis only examined responses of students aged 13-15 years who completed the survey in a classroom; it does not include youth who were not enrolled in school or who were absent on the day the questionnaire was administered. In sub-Saharan Africa, about one third of youth do not attend school; therefore, the survey is not representative to all youth (26). Second, the questionnaire was self-administered and self-reported; thus, students may under report smoking behavior. Third, some methods of obtaining cigarettes may be under-reported because respondents can only choose one answer to the question on the method of obtaining cigarettes. Finally, the cross-sectional design of the study does not allow for causal analyses between student access to cigarettes and cigarette usage.

\section{Conclusions}

The pressing need for interventions related to infectious diseases, coupled with perceived low smoking prevalence, have resulted in tobacco control being a low priority in the sub-Saharan African region $(8,27,28)$. The situation is compounded by the fact that unlike adult smoking prevalence, smoking among youth in the region is higher than in many developed countries (8). Moreover, economic growth and stronger tobacco industry presence in the region have resulted in an increase in smoking prevalence, particularly among the vulnerable youth population $(6,8)$. Without implementation and enforcement of evidence-based tobacco prevention and control interventions, it is estimated that 
cigarette smoking prevalence will rise from $15.8 \%$ in 2010 to $21.9 \%$ in 2030 (29). This would signify the largest projected regional increase in the world (29). Implementation and enforcement of legislation that prohibits youth access to cigarettes may help reduce the burden of tobacco use in these countries.

\section{Conflict of Interest}

This publication was supported by grants from Bloomberg Philanthropies and the Bill \& Melinda Gates Foundation. Bloomberg Philanthropies and Bill \& Melinda Gates Foundation did not have any role in data analysis, interpretation of results, decision to publish, or preparation of the manuscript.

\section{Acknowledgements}

Financial support for this research is provided by the Bloomberg Initiative to Reduce Tobacco Use through the CDC Foundation with a grants from Bloomberg Philanthropies and the Bill \& Melinda Gates Foundation.

\section{Disclaimer}

The findings and conclusions in this report are those of the authors and do not necessarily represent the official positions of the U.S. Centers for Disease Control and Prevention. 


\section{References}

1. World Health Organization. WHO Global Report: Mortality Attributable to Tobacco. Geneva: 2012.

2. Eriksen M, Mackay J, Ross H. The Tobacco Atlas, Fourth Edition. Atlanta, GA; New York, NY: American Cancer Society, World Lung Foundation; 2012.

3. U.S. Department of Health and Human Services. Preventing tobacco use among youth and young adults: A report of the Surgeon General. Atlanta, GA: U.S. Department of Health and Human Services, Centers for Disease Control and Prevention, National Center for Chronic Disease Prevention and Health Promotion, Office on Smoking and Health; 2012.

4. BMA Board of Science. Breaking the cycle of children's exposure to tobacco smoke. British Medical Association; London, UK: 2007.

5. Stead L \& Lancaster T. Interventions for preventing tobacco sales to minors. Cochrane Database of Systematic Reviews 2005, Issue 1.

6. World Health Organization. WHO Report on the Global Tobacco Epidemic, 2013: Enforcing bans on tobacco advertising, promotion and sponsorship. 2013.

7. Euromonitor International: Still a Smoker's paradise: a snapshot of the lighting-up culture in the Middle East and Africa. 2012.

8. Blecher E \& Ross H. Tobacco Use in Africa: Tobacco Control Through Prevention. Atlanta, GA: American Cancer Society; 2013.

9. World Health Organization. WHO Framework Convention on Tobacco Control, Geneva, Switzerland: 2003.

10. CDC - Global Tobacco Surveillance System Data - Global Youth Tobacco Survey - Overview. http://nccd.cdc.gov/gtssdata/Ancillary/Documentation.aspx?SUID=1\&DOCT=1. March 25, 2014.

11. Warren C, Lee J, Lea V, Goding A, O'Hara B, Carlberg M, et. al. Evolution of the Global Tobacco Surveillance System 1998-2008. Glob Health Promot, 2009; 16:04.

12. Tobacco Products Control Act 83, 1993. Available at: http://www.tobaccocontrollaws.org/files/live/South\%20Africa/South\%20Africa\%20\%20Tobacco\%20Products\%20Control\%20Act\%20-\%20national.pdf

13. Campaign For Tobacco Free Kids. Enforcing Laws Prohibiting Cigarette Sales to Kids Reduces Youth Smoking, 2010. 
14. World Health Organization. Reporting Instrument of the WHO Framework Convention on Tobacco Control - Ghana, 2012. Available at: http://www.who.int/fctc/reporting/party_reports/ghana_2012_report_final.pdf.

15. World Health Organization. Reporting Instrument of the WHO Framework Convention on Tobacco Control - Republic of Congo, 2012. Available at: http://www.who.int/fctc/reporting/congo_report.pdf?ua=1.

16. World Health Organization. Reporting Instrument of the WHO Framework Convention on Tobacco Control - Swaziland, 2012. Available at:

http://www.who.int/fctc/reporting/party_reports/swaziland_2012_report.pdf.

17. Campaign For Tobacco Free Kids. Tobacco Control Laws, Country Details for Uganda, 2016. Accessible at: http://www.tobaccocontrollaws.org/legislation/country/uganda/summary.

18. Tobacco Control Bill, 2014. Available at: http://parliamentwatch.ug/wpcontent/uploads/2015/02/The-tobacco-control-bill-2014.pdf.

19. Jason L, Berk M, Schnoop-Wyatt D, Talbot B. Effects of enforcement of youth access laws on smoking prevalence. Am J Community Psychol, 1991; 27.2: 143-160.

20. Levy D, Chaloupka F, Sandy S. Expert Opinions on Optimal Enforcement of Minimum Purchase Age Laws for Tobacco. Public Health Mgmt \& Practice, 2000; 6.3: 107-114.

21. World Health Organization. Parties to the WHO Framework Convention on Tobacco Control, 2015. Available from: http://www.who.int/fctc/signatories_parties/en/index.html.

22. Altman D, Rasenick-Douss L, Foster V, Tye J. Sustained effects of an educational program to reduce sales of cigarettes to minors. Am J Public Health, 1991; 81: 891-893.

23. Jason L, Billows W, Schnoop-Wyatt D, King C. Reducing the illegal sales of cigarettes to minors: analysis of alternative enforcement schedules. J Appl Behav Anal, 1996; 29.3: 333-344.

24. Forster J \& Wolfson M. Youth Access to Tobacco: Policies and Politics. Annual Rev of Pub Health, 1998; 19:203-235.

25. Leatherdale $S \&$ Strath J. Tobacco Retailer Density Surrounding Schools and Cigarette Access Behaviors Among Underage Smoking Students. Ann Behav Med, 2007; 33.1: 105-111.

26. UNESCO Institute for Statistics. Fixing the broken promise of education for all: Findings on the global initiative on out-of-school children. Montreal, Quebec: 2015.

27. Network of African Science Academies. Preventing a tobacco epidemic in Africa: A call for effective action to support health, social, and economic development. Nairobi, Kenya: 2014. 
Report of the Committee on the Negative Effects of Tobacco on Africa's Health, Economy, and Development.

28. Drope J. (Ed.). Tobacco control in Africa: People, politics, and policies. London: Anthem Press: 2011.

29. Mendez D, Alshanqeety O, Warner K. The potential impact of smoking control polices on future global trends. Tob Control, 2013; 22:46-51. 
Table 1. Survey sample size and response rate, Global Youth Tobacco Survey (GYTS), 2009-2011, six SubSaharan African countries

\begin{tabular}{lcccc} 
Country & $\begin{array}{c}\text { Year GYTS } \\
\text { conducted }\end{array}$ & $\begin{array}{c}\text { Number of } \\
\text { schools }\end{array}$ & $\begin{array}{c}\text { Sample size } \\
\text { (13-15 year old } \\
\text { students) }\end{array}$ & $\begin{array}{c}\text { Overall response } \\
\text { rate }\end{array}$ \\
\hline Cote d'Ivoire & 2009 & 41 & 1,920 & $82.0 \%$ \\
\hline Ghana & 2009 & 57 & 4,171 & $84.0 \%$ \\
\hline Republic of Congo & 2009 & 29 & 1,141 & $69.7 \%$ \\
\hline South Africa & 2011 & 192 & 3,947 & $69.1 \%$ \\
\hline Swaziland & 2009 & 30 & 1,239 & $97.0 \%$ \\
\hline Uganda & 2011 & 50 & 2,026 & $83.3 \%$ \\
\hline
\end{tabular}

${ }^{\mathrm{a} G l o b a l ~ Y o u t h ~ T o b a c c o ~ S u r v e y ~}$ 
Table 2. Method of obtaining cigarettes among students aged 13-15, Global Youth Tobacco Survey (GYTS), 2009-2011, six Sub-Saharan African countries

\begin{tabular}{|c|c|c|c|c|c|c|}
\hline & Cote D'Ivoire & Ghana & $\begin{array}{l}\text { Republic of } \\
\text { Congo }\end{array}$ & South Africa & Swaziland & Uganda \\
\hline & \multicolumn{6}{|c|}{ Weighted percentage $(95 \% \mathrm{CI})$} \\
\hline $\begin{array}{l}\text { Current } \\
\text { Cigarette } \\
\text { Smokers }^{a}\end{array}$ & $\begin{array}{l}13.7(11.0- \\
16.9)(n=1,821)\end{array}$ & $\begin{array}{l}3.6(2.3-5.7) \\
(n=3,814)\end{array}$ & $\begin{array}{l}8.2(6.3-10.5) \\
(n=1,049)\end{array}$ & $\begin{array}{l}12.7(10.9- \\
14.7)(n=3,713)\end{array}$ & $\begin{array}{l}6.4(4.2-9.4) \\
(n=1,192)\end{array}$ & $\begin{array}{l}4.8(3.2-7.2) \\
(n=1,909)\end{array}$ \\
\hline \multicolumn{7}{|c|}{ Method of obtaining cigarettes (among cigarette smokers) } \\
\hline $\begin{array}{l}\text { Bought in } \\
\text { store/shop }\end{array}$ & $\begin{array}{l}27.4(20.9- \\
35.1)(n=236)\end{array}$ & $\begin{array}{l}26.9(18.4- \\
37.5)(n=110)\end{array}$ & $\begin{array}{l}37.7(25.2- \\
52.1)(n=85)\end{array}$ & $\begin{array}{l}52.6(43.2- \\
61.8)(n=419)\end{array}$ & $\begin{array}{l}28.2(17.2- \\
42.7)(n=67)\end{array}$ & $\begin{array}{l}22.6(11.2- \\
40.2)(n=68)\end{array}$ \\
\hline $\begin{array}{l}\text { Bought from } \\
\text { vending } \\
\text { machine }\end{array}$ & $\begin{array}{l}0.8(0.2-3.3) \\
(n=236)\end{array}$ & $\begin{array}{l}6.6(2.6-15.7) \\
(n=110)\end{array}$ & $\begin{array}{l}1.8(0.2-13.1) \\
(n=85)\end{array}$ & $\begin{array}{l}2.5(1.2-5.2) \\
(n=419)\end{array}$ & $\begin{array}{l}1.6(0.2-11.6) \\
(n=67)\end{array}$ & $\begin{array}{l}5.8(1.2-24.5) \\
(n=68)\end{array}$ \\
\hline $\begin{array}{l}\text { Someone else } \\
\text { bought }\end{array}$ & $\begin{array}{l}4.1(1.8-9.2) \\
(n=236)\end{array}$ & $\begin{array}{l}18.1(9.1-32.8) \\
(n=110)\end{array}$ & $\begin{array}{l}12.8(7.3-21.5) \\
(n=85)\end{array}$ & $\begin{array}{l}10.4(6.9-15.3) \\
(n=419)\end{array}$ & $\begin{array}{l}9.4(3.5-22.6) \\
(n=67)\end{array}$ & $\begin{array}{l}21.1(11.5- \\
35.5)(n=68)\end{array}$ \\
\hline Borrowed & $\begin{array}{l}17.7(13.8- \\
22.5)(n=236)\end{array}$ & $\begin{array}{l}6.4(3.2-12.7) \\
(n=110)\end{array}$ & $\begin{array}{l}14.0(4.5-35.9) \\
(n=85)\end{array}$ & $\begin{array}{l}10.7(7.4-15.3) \\
(n=419)\end{array}$ & $\begin{array}{l}3.2(0.9-10.9) \\
(n=67)\end{array}$ & $\begin{array}{l}11.5(5.0-24.3) \\
(n=68)\end{array}$ \\
\hline Stole & $\begin{array}{l}1.9(0.7-5.0) \\
(n=236)\end{array}$ & $\begin{array}{l}6.0(3.0-12.0) \\
(n=110)\end{array}$ & $\begin{array}{l}12.1(7.7-18.5) \\
(n=85)\end{array}$ & $\begin{array}{l}9.9(5.2-18.2) \\
(n=419)\end{array}$ & $\begin{array}{l}16.9(8.0-32.3) \\
(n=67)\end{array}$ & $\begin{array}{l}12.5(5.2-27.2) \\
(n=68)\end{array}$ \\
\hline $\begin{array}{l}\text { Got from older } \\
\text { person }\end{array}$ & $\begin{array}{l}33.2(25.6- \\
41.7)(n=236)\end{array}$ & $\begin{array}{l}9.1(5.4-15.0) \\
(n=110)\end{array}$ & $\begin{array}{l}8.1(3.2-19.3) \\
(n=85)\end{array}$ & $\begin{array}{l}5.6(3.6-8.6) \\
(n=419)\end{array}$ & $\begin{array}{l}21.6(9.8-41.2) \\
(n=67)\end{array}$ & $\begin{array}{l}9.1(1.9-34.4) \\
(n=68)\end{array}$ \\
\hline Other way & $\begin{array}{l}14.9(10.7- \\
20.2)(n=236)\end{array}$ & $\begin{array}{l}26.8(13.2- \\
46.9)(n=110)\end{array}$ & $\begin{array}{l}13.4(3.0-43.8) \\
(n=85)\end{array}$ & $\begin{array}{l}8.4(5.5-12.6) \\
(n=419)\end{array}$ & $\begin{array}{l}19.0(10.8- \\
31.4)(n=67)\end{array}$ & $\begin{array}{l}17.4(7.6-35.1) \\
(n=68)\end{array}$ \\
\hline \multicolumn{7}{|c|}{ Refusal of sales due to age (among cigarette smokers) } \\
\hline No & $\begin{array}{l}68.9(51.0- \\
82.5)(n=55)\end{array}$ & $\begin{array}{l}53.8(32.0- \\
74.3)(n=20)^{b}\end{array}$ & $\begin{array}{l}47.6(19.2- \\
77.6)(n=22)^{b}\end{array}$ & $\begin{array}{l}68.7(59.5- \\
76.6)(n=196)\end{array}$ & $\begin{array}{l}56.9(32.6- \\
78.2)(n=19)^{b}\end{array}$ & $\begin{array}{l}35.6(7.1-79.8) \\
(n=11)^{a}\end{array}$ \\
\hline \multicolumn{7}{|c|}{ Offered free cigarettes (among all students) } \\
\hline Yes & $\begin{array}{l}4.7(3.7-6.1) \\
(n=1,899)\end{array}$ & $\begin{array}{l}11.2(9.1-13.7) \\
(n=4,063)\end{array}$ & $\begin{array}{l}7.9(5.2-11.9) \\
(n=1,119)\end{array}$ & $\begin{array}{l}12.1(10.1- \\
14.5)(n=3,826)\end{array}$ & $\begin{array}{l}7.8(6.3-9.7) \\
(n=1,230)\end{array}$ & $\begin{array}{l}10.7(7.6-14.6) \\
(n=1,976)\end{array}$ \\
\hline
\end{tabular}

a $\mathrm{n}$ is based on those who answered the question, "In the past 30 days, on how many days did you smoke cigarettes?".

Participants who did not answer this question were categorized as missing.

${ }^{b}$ Estimates are instable as they were calculated using $<35$ cases and thus should be interpreted with caution. 
Table 3. World Health Organization (WHO) Framework Convention on Tobacco Control (FCTC) status and legislation prohibiting minors from purchasing cigarettes.

\begin{tabular}{|c|c|c|c|c|}
\hline Country & $\begin{array}{l}\text { WHO FCTC } \\
\text { signed and } \\
\text { ratified }\end{array}$ & $\begin{array}{c}\text { Year WHO FCTC } \\
\text { entered into } \\
\text { force }\end{array}$ & $\begin{array}{l}\text { Legislation defining legal age } \\
\text { for purchasing cigarettes }\end{array}$ & $\begin{array}{c}\text { Legal age to } \\
\text { purchase } \\
\text { cigarettes }\end{array}$ \\
\hline Cote d'Ivoire & Yes & 2010 & No legislation & $\begin{array}{c}\text { No legal age } \\
\text { defined }\end{array}$ \\
\hline Ghana & Yes & 2005 & Public Health Act, 2012 & 18 \\
\hline \multirow[t]{2}{*}{ Republic of Congo } & Yes & 2007 & Tobacco Control Act, 2012 & 18 \\
\hline & & & Tobacco Products Control Act & \\
\hline \multirow[t]{2}{*}{ South Africa } & Yes & 2005 & 83 of 1993 & 18 \\
\hline & & & Tobacco Products Control Act, & \\
\hline Swaziland & Yes & 2006 & 2013 & 18 \\
\hline Uganda & Yes & 2007 & Tobacco Control Act, 2015 & 21 \\
\hline
\end{tabular}

